\title{
CARING FOR OUR PATIENTS FACT OR LEGEND - AN ECONOMIC VIEW
}

\author{
Professor Shirley B. Williamson \\ Head, Department of Nursing, \\ University of the Witwatersrand
}

T HE debate on economic aspects of health care is beset with the conflict of balancing supply and demand, of offering a less adequate service to all people, or a maximal service to relatively few. Somewhere along this continuum is an area of optimal service; providing a range of services which the country can afford, the point at which we can best cut our coat to fit our cloth.

It is over to the health professionals to make the best use of the economic input, they are the vital manpower elements and the utilisation of resources is in their hands.

Can there be any blue print or prescribed answers? for these are surely problems which each country must see against its own sociological background and varying health needs - yet being ever mindful that needs and expectations are not always synonomous.

The resources are limited - no matter how large the health budget may sound - it is still necessary to make choices in the dilution of services and compromises between ideals and possibilities in realistic economic and social terms.

In this country the sources of such funds for services may arise in direct payments by the individual, from employer-employee schemes, insurances, benefits or aids, and State funds to which the population contribute directly or indirectly.

Various criteria as to the effectiveness of our programmes have been suggested. Mechanic ${ }^{(5)}$ for one, sites such factors as mortality and morbidity rates, costs, quality of services and controls, but these are doubtful indicators, for medical care is a highly intangible product, not as much regulated by the health or sickness of the population as by the level of provision of the services. Consultations and investigations are limited where the services are scarce and expensive, yet when readily available it is common for the number of visits to increase - and patients present with less serious conditions.

Within this general statement there is a controversial thought - that where the population is sparse a basic essential service is offered. This often better meets the needs of the majority of the community - a simpler cost effective service. (The hospital costs in S.A. range from $\pm R 8,00$ to $R 82,00$ per patient per day) $)^{(4)}$.

Inevitably the doctors have a tremendous impact on the type of service, the levels of specialisation, the equipment which can be demanded the level of medical technology. Their practice influences the number of beds and the average length of stay in hospital. (Director of Hospital Services T.V.L. reports length of patient's stay as Whites 5,8; non-Whites 8,5 days) ${ }^{(8)}$.

The allocation of our resources is fraught with ethical dilemmas. There are never enough resources - take kidney or dyalisis machines for example. Jennett writes on "The Cost of Rescue and the Price of Survival"; elaborating on the complex balance of cure, care, and rescue.

Are we saving the disabled? Do such heroic measures result in survival with mental and physical disability, and a life of dependence at enormous economic outlay? ${ }^{(6-46-51)}$. Critical analysis at this level causes one to look at what Fry calls the unnecessary expense and care given to the non-curable, he calls for more honesty and less therapeutic endeavours which would benefit the patient, his comfort, his pocket and the national exchequer ${ }^{(6}$ pl4) $^{2}$.

The highest quality of care is the vital element in these critical care areas, and a large slice of the economic cake is available to such prestige areas. Yet one asks, is not every ill person entitled to this high level of skill to meet his needs? Keeping in mind that society is reassured by witnessing reasonable efforts being made to save lives even if these are not always successful.

Accepting that the hospital services are the most expensive part of the health system, let us take a critical look at our traditional practice - for example:

- It is suggested that a patient suffering from an acute myocardial infarction could and may be should be cared for at home.

- District nursing could keep many patients out of hospital; happy in their own environments, at their own domestic cost.

Well within the scope of the registered nurse is the development of primary care services, providing a better service, nearer to the patient, and at a time when he can utilise it. Is the $8-5$ clinic meeting the needs of the worker? - I think not!

- Self care may be more effective an less expensive, but do we educate adequatley or is this where medicine and money is wasted?

- Should we not be reducing what Brocklehurst calls “Multi-diciplinary Madness"'(6 p87) avoiding duplication 
and facilitating greater co-operation in our services?

If our ultimate aim is high quality patient care, then what really provides patient satisfaction?

There are many questions as yet unanswered. I make a plea for more research in this field of cost containment and an inservice education programme on research appreciation for those involved, that htey may interpret and act on the findings and realise the worth of the project.

More research - not a popular item of expenditure - the outcomes are often uncertain and generally uncomfortable - such indirect expenditure is not appreciated - it is too far removed from "our" patient. Yet today change must be justified and brough about through systematic study and scientific analysis; such expenditure is resisted by the protagonists of stagnation - of whom there are regrettably many. hence allocations for higher education, for studies in cost benefit analyses are thinly spread. Reliable relevant data upon which to base our rational decisions for health planning are vital to true care.

Studies in quality controls will naturally focus on the nurse, for responsibility for the quality of care which the patient actually receives falls squarely on the shoulders of the nurse, for the nurse is in the key position to manimpulate the resources of men and materials, it is the nurse who co-ordinates the contribution of the whole health team and converts it to care. In her hands lies the assesment of patient needs, much of the decision making, the implementation of the nursing care plan and the final evaluation. It is the nurse who interprets, implements and records the care given.

Is the nurse aware, that it is she who is manipulating the health budget - the millions of rands? Perhaps if she perceives her contribution in its true perspective she would gain greater satisfaction which would be reflected in her work, and again if this aspect were given the recognition it deserves by other disiplines her status and security would be assured.

Could lack of recognition, lack of self esteem be equated with economic loss?

Are the personnel adequate in quality as well as quantity? Is the correct level of person being utilised for the service required? Are the lesser qualified being exploited beyond their capabilities, or is potential being under utilised?

Where nurses are not extending themselves they loose motivation, they drift and become dissatisfied, inevitably giving a lesser level of care - here we have both nurse and patient at risk - surely an economic liability. Such loss of humane concern outweighs all other deficiencies and is indeed the most likely cause of carelessness and neglect, and the resources essential for care.

Economic factors underlie also the supply of nurse manpower. It is doubtful if the number of nursing posts have increased in relation to population growth, never the intensity of the service, posts have been frozen due to economic stringencies and the Report on the Nursing Service ${ }^{(7)}$ is witness to the number of vacant posts. Could such shortages be due to lack of economic reward?

Would such a bleak picture not affect our patient care, our levels of supervision, and in the long term, the recruitment to the nursing profession? Would the position not ultimately improve if the powers that be, took their courge in both hands and changed the ratio of registered to non-registered nurses, that the registered nurse might actively nurse patients? Employ her to do the job for which by she has received a relatively expensive training.

The Registered Nurse is surely our greatest asset.

Utilise her in the work she has been qualified to do and from which she derives the greatest satisfaction. In so doing she will educate the neophyte to give systematic individualised care, conveying not only her manual skills, but also her communication and judgmental skills; she would maintain innovative, planned quality care where it belongs - caring for our patients.

\section{REFERENCES:}

1. Abel-Smith B. An International Study of Health Expenditure. Public Health Papers No. 321967 W.H.O. Geneva.

Anderson O.W. Health Care: Can there be Equity? 1972 John Wiley. New York p.23. Cooper, M.H. \& Culyer A.J.Ed. Healıh Economics. 1973 Penguin Books.

4. Hospital and Nursing Year Book 1979.

5. Mechanic D. Public Expectations and Health Care. 1972 Wiley-Interscience New York pp 295-300.

6. Phillips C.I. \& Wolfe J.N. Ed. Clinical Practice and Economics 1977 Pitmann Medical London.

7. Report on Nursing Service in the Republic of S.A. and the Self-Governing Terrirotires 1978

8. Report of the Director of Hospital Services 1977/78

9. Star 15th August 1979 